PREPARED FOR THE U.S. DEPARTMENT OF ENERGY, UNDER CONTRACT DE-AC02-76CH03073

PPPL-3964

PPPL-3964

UC-70

Three-dimensional Simulation

of Gas Conductance Measurement Experiments on Alcator C-Mod

by

D.P. Stotler and B. LaBombard

June 2004

NM|

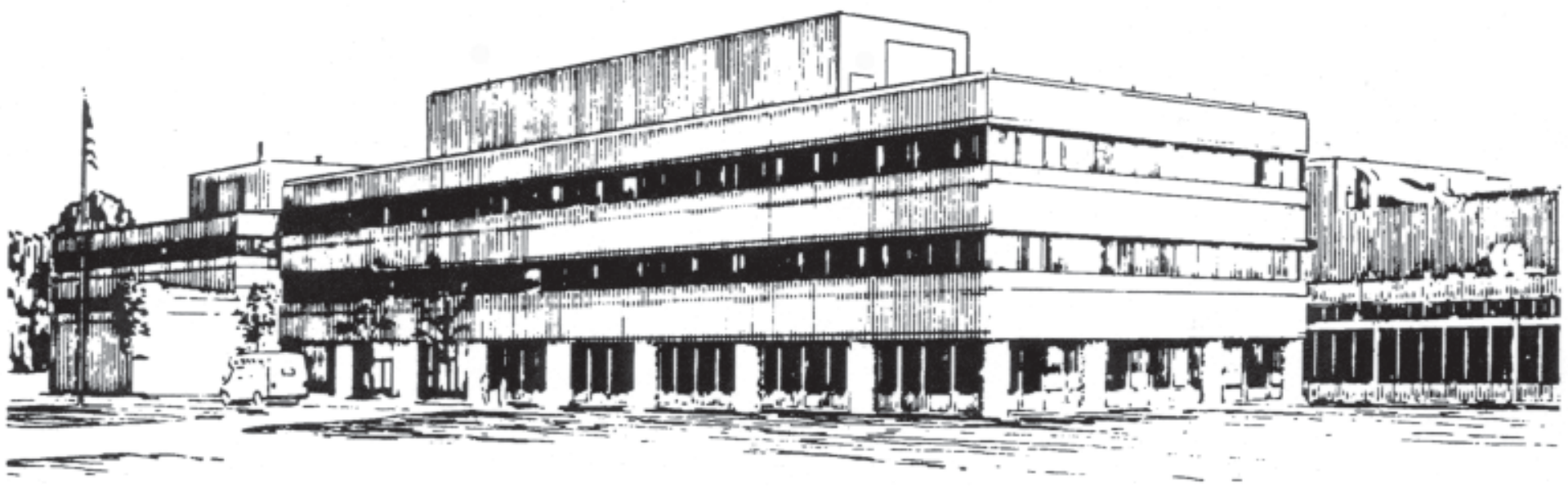

PRINCETON PLASMA PHYSICS LABORATORY PRINCETON UNIVERSITY, PRINCETON, NEW JERSEY 


\section{PPPL Reports Disclaimer}

This report was prepared as an account of work sponsored by an agency of the United States Government. Neither the United States Government nor any agency thereof, nor any of their employees, makes any warranty, express or implied, or assumes any legal liability or responsibility for the accuracy, completeness, or usefulness of any information, apparatus, product, or process disclosed, or represents that its use would not infringe privately owned rights. Reference herein to any specific commercial product, process, or service by trade name, trademark, manufacturer, or otherwise, does not necessarily constitute or imply its endorsement, recommendation, or favoring by the United States Government or any agency thereof. The views and opinions of authors expressed herein do not necessarily state or reflect those of the United States Government or any agency thereof.

\section{Availability}

This report is posted on the U.S. Department of Energy's Princeton Plasma Physics Laboratory Publications and Reports web site in Fiscal Year 2004. The home page for PPPL Reports and Publications is: http://www.pppl.gov/pub_report/

DOE and DOE Contractors can obtain copies of this report from:

U.S. Department of Energy

Office of Scientific and Technical Information

DOE Technical Information Services (DTIS)

P.O. Box 62

Oak Ridge, TN 37831

Telephone: (865) 576-8401

Fax: (865) 576-5728

Email: reports@adonis.osti.gov

This report is available to the general public from:

National Technical Information Service

U.S. Department of Commerce

5285 Port Royal Road

Springfield, VA 22161

Telephone: $1-800-553-6847$ or

(703) $605-6000$

Fax: (703) 321-8547

Internet: http://www.ntis.gov/ordering.htm 


\title{
Three-dimensional simulation of gas conductance measurement experiments on Alcator C-Mod
}

\author{
D.P. Stotler ${ }^{\mathrm{a}, *}$, and B. LaBombard ${ }^{\mathrm{b}}$ \\ a Princeton Plasma Physics Laboratory, Princeton University, P. O. Box 451, \\ Princeton, NJ 08543-0451, USA \\ ${ }^{\mathrm{b}}$ MIT Plasma Science and Fusion Center, NW17, Cambridge, MA 02139, USA
}

\begin{abstract}
Three-dimensional Monte Carlo neutral transport simulations of gas flow through the Alcator C-Mod subdivertor yield conductances comparable to those found in dedicated experiments. All are significantly smaller than the conductance found with the previously used axisymmetric geometry. A benchmarking exercise of the code against known conductance values for gas flow through a simple pipe provides a physical basis for interpreting the comparison of the three-dimensional and experimental C-Mod conductances.
\end{abstract}

Key words: Alcator C-Mod, Neutral gas modeling, DEGAS 2 code PACS: 51.10.+y, 52.65.Pp

\section{Introduction}

Monte Carlo simulations of the neutral gas behavior in the Alcator C-Mod divertor have yielded neutral pressures that are a factor of 10 smaller than those observed[1]. Lisgo[2] has greatly reduced the discrepancy by examining a variety of physics assumptions in the plasma and neutral transport models and by devising and applying improved models as needed. In particular, the approximate, axisymmetric representation of the neutral gas pathways through the three-dimensional (3-D) C-Mod subdivertor has been found to be significantly inaccurate.

A series of detailed experiments has been undertaken to measure the gas conductances through the C-Mod vacuum vessel so that the neutral transport models can be accurately benchmarked[3]. For the neutral pressures used in these measurements, typical of C-Mod discharges, the neutral gas transport is in the transition regime between molecular and viscous flow[2]. A 3-D, nonlinear Monte Carlo neutral transport code, like DEGAS 2[4], can in principal deal with flows of this type as well as treat the geometry in as much detail as is needed to replicate

* Corresponding and presenting author

Email address: dstotler@pppl.gov (D.P. Stotler). 
these experiments. We will evaluate its ability to do so and compare the resulting 3-D gas conductances with those obtained using an axisymmetric representation of the sort employed previously.

\section{Gas Flow Fundamentals}

\subsection{Two Chamber Model}

For the purpose of defining the quantities of interest (see, for example, [5]), and to aid in the interpretation of the experimental and computational results, consider two volumes, $V_{1}$ and $V_{2}$, at pressures $p_{1}$ and $p_{2}$, connected by a narrow opening. A source of gas, $Q_{1}$, is introduced into the first volume and a sink, $Q_{2}$, in the second volume. Gas flows from the first volume into the second at a rate $Q_{12}$ determined by the conductance of the opening

$$
U_{12}=Q_{12} /\left(p_{1}-p_{2}\right)
$$

We first set the sink $Q_{2}=0$, take $U_{12}$ to be a constant, and specify the pressures at $t=0$. The time dependent solution of the equations describing this system has an initial transient that dies out for $t \gg V_{1} V_{2} / U_{12}\left(V_{1}+V_{2}\right)$, leading to a steady pressure differential

$$
p_{1}-p_{2}=\frac{1}{U_{12}} \frac{V_{2} Q_{1}}{V_{1}+V_{2}}
$$

If we add a pump of speed $S$ to the second volume so that $Q_{2}=S p_{2}$, we have instead steady state solutions

$$
p_{1}=Q_{1}\left(\frac{1}{S}+\frac{1}{U_{12}}\right), \quad p_{2}=\frac{Q_{1}}{S} .
$$

\subsection{Physics Model}

The only atomic physics process in this paper is the elastic scattering of $D_{2}$ molecules off each other. An iterative, BGK treatment [6,7] is used with a reaction rate[8] $\langle\sigma v\rangle=k T / \eta$, where $T$ is the gas temperature, and $\eta$ is the experimentally measured viscosity.

Molecules striking material surfaces are absorbed and desorbed with $100 \%$ recycling. The desorbed molecules are sampled from a room temperature (300 K) Maxwell flux distribution. All gas sources have a room temperature Gaussian energy distribution with a cosine angular distribution.

\subsection{Simple Test Case}

We can validate the DEGAS 2 physics model and illustrate the change in conductance with flow regime by comparing the code with known conductances for a relatively simple geometry. 
Fluid flow regimes are characterized by the dimensionless ratio $K=\lambda / d$, the Knudsen number, where $\lambda$ is the mean free path and $d$ is a characteristic size of the cross section through which the gas is flowing [5]. For the $D_{2}$ elastic scattering process, $\lambda=10^{-2} / p(\mathrm{~Pa}) \mathrm{m}$. In the "molecular flow" regime, $K>3$, the molecules collide more frequently with the vessel walls than with each other. At the opposite extreme is the "viscous" flow regime, $K<0.01$. The "transition" regime lies between these two limits.

We consider a $1 \mathrm{~m}$ long rectangular box divided into two volumes connected by a $0.205 \mathrm{~m}$ long, $0.1 \mathrm{~m}$ square pipe. The molecular flow conductance for this case is

$$
U_{m f}=A \frac{\bar{v}}{4} W
$$

where $A=10^{-2} \mathrm{~m}^{2}$ is the cross sectional area, $\bar{v}$ is the mean molecular velocity, $\bar{v} / 4=314$ $\mathrm{m} / \mathrm{s}$, and $W=0.38$ is the transmission probability through the pipe[5]. The viscous flow conductance is $[5]$

$$
U_{v f}=\frac{1}{12 \eta} \frac{a^{2} b^{2}}{L} \bar{p} Y
$$

where $a, b$ are the sides of the opening, $L$ is its length, $\bar{p}$ is the average of the pressures on either side of the opening, and $Y=0.422$ is a numerical factor[5].

The conductances for five simulations are compared with Eqs. (4) and (5) Fig. 1. We present these data as a function of $Q_{1}$ since it is an independent variable in the simulations, using Eqs. (1) and (3) to get $U_{v f}\left(Q_{1}\right)$.

The two lowest $Q_{1}$ simulations are at or near the molecular flow regime, as indicated by the gray bar in Fig. 1. The conductance values for these two runs are within $2 \%$ of the expected value.

In the viscous flow regime, the fluid velocity through the pipe is a maximum at the center and goes to zero at the walls, as is required by the "no slip" boundary condition there. To determine whether or not we are adequately resolving the flow shear, two $Q_{1}=0.41 \mathrm{~J} / \mathrm{s}$ ( $K \simeq 0.1$ ) runs have been done, one with 16 zones (smaller $U_{12}$ ) spanning the pipe and one with 64 zones. That different conductances result implies that spatial resolution of the flow is an issue. Evaluating the adequacy of 64 zones can only be done by comparing with another run with even finer resolution. This phenomenon also appears to result in a too low conductance for the highest $Q_{1}$ simulation, even though it likewise has 64 zones spanning the opening.

\section{Experimental Conductance Values}

A set of gas-puff capillaries and in-situ pressure gauges have been installed in Alcator C-Mod to permit the measurement of gas flows and conductances through the divertor structures[3] considered in [1] and [2]. We will focus on the gas flow through "closed" and "open" ports. In the former, the principal gas pathway between the main chamber / divertor and the divertor plenum ("gas box") / bottom pumping port volumes is a small slot underneath the outer 
divertor. In an "open" port, the divertor tiles and support structure enclosing the gas box have been removed to facilitate diagnostic access.

The gas source, situated at the bottom outer edge of the gas box (Fig. 2), is calibrated by dividing the rate of rise of the main chamber neutral pressure by the torus volume. The volume $V_{1}$ corresponds to the gas box and bottom port; $V_{2}$ corresponds to everything else. The timescale of the transient mentioned in Sec. 2.1 is on the order of milliseconds, much less than the 1-2 seconds over which the pressures are measured. Since $V_{1} \ll V_{2}$, Eq. (2) is equivalent to Eq. (1), The pressure $p_{1}$ is provided by a gauge at the bottom of the port below the gas capillary, and $p_{2}$ is given by a gauge adjacent to the main chamber. These pressure values rise uniformly while the capillary is open, but their difference, and hence the conductance, remains fairly constant. The gas flow is, thus, at or near the molecular flow regime.

In the "closed" divertor case, the bottom port pressure climbs from 2.9 to $3.6 \mathrm{~Pa}$; the main chamber pressure starts at $1.1 \mathrm{~Pa}$ and finishes at 2.0. The conductance holds steady at about $1.2 \mathrm{~m}^{3} / \mathrm{s}$. When the analogous experiment is performed at an "open" port, the bottom pressure goes from 1.3 to $2.0 \mathrm{~Pa}$ while the main chamber pressure increases from 0.8 to $1.7 \mathrm{~Pa}$. The conductance again does not vary much, hovering around $4.5 \mathrm{~m}^{3} / \mathrm{s}$.

\section{Alcator C-Mod Simulations}

The toroidal variation of the C-Mod vacuum vessel and divertor hardware can be roughly described by a "pie slice" model in which the various structures are represented as plane figures revolved about the major axis of the torus through a range of toroidal angles. Such a representation can be handled by a modest extension of the existing 2-D geometry setup tools used with DEGAS 2[1].

Some of the plane "polygons" we use are overlaid on a drawing of the actual C-Mod hardware in Fig. 2 [3]. The radial width of the vertical pumping ports has been reduced to match the cross sectional area of the actual port shape.

Most of the toroidal variation is associated with the pumping ports, the outer divertor plates / tiles, and the divertor mounting hardware (located in the gas box). The pumping ports are treated as vacuum regions $6^{\circ}$ wide, extending vertically to $Z= \pm 1.9 \mathrm{~m}$, at toroidal locations corresponding to each of the $10 \mathrm{C}$-Mod bays. The divertor mounting hardware (including the "gusset plates") are modeled as $6^{\circ}$ solid regions on either side of these ports; at other toroidal angles these volumes are treated as vacuum. The outer divertor plates and tiles are present everywhere except at the 5 "open" bays that are spanned by a $6^{\circ}$ vacuum gap. At the other 5 "closed" bays, there is also a narrow, $3 \mathrm{~mm}$ gap that allows for thermal expansion. Following Lisgo[2], we include a small poloidal gap of either 0,2 , or $4 \mathrm{~mm}$ at the top of the gas box to simulate the effect of holes in the insulating material that fills the space between the gas plate and vacuum vessel.

A toroidally localized gas puff source is specified at the bottom edge of the gas box. Since these DEGAS 2 simulations need to be time independent, we establish a pumping surface with an albedo of $90 \%$ at the top of the upper pumping ports.

Figure 3 shows the pressure variation in the "closed" port simulation. The port containing 


\begin{tabular}{lcccc}
\hline Run & $p_{1}(\mathrm{~Pa})$ & $p_{2}(\mathrm{~Pa})$ & $Q_{1}(\mathrm{~J} / \mathrm{s})$ & $U_{12}\left(\mathrm{~m}^{3} / \mathrm{s}\right)$ \\
\hline Axisymmetric & 0.21 & 0.16 & 1.99 & 40. \\
Open & 1.46 & 1.22 & 1.86 & 7.8 \\
Closed (base) & 3.7 & 1.29 & 1.99 & 0.83 \\
2 mm pol. gap & 3.9 & 1.30 & 1.99 & 0.76 \\
Reduce source & 0.26 & 0.085 & 0.124 & 0.71 \\
Increase source & 16.5 & 5.0 & 8.0 & 0.69 \\
\hline Table 1 & & & &
\end{tabular}

Table 1

Results from Alcator C-Mod simulations. The closed port base run for the variations uses a $4 \mathrm{~mm}$ gap at the top of the gas box.

the source is on the lower left of the figure. Toroidal flow into adjacent adjacent ports through the gap between the outer divertor plate and the floor tiles is evident in the central slice The pressure is nearly constant everywhere else in the problem

The results from some of the runs are summarized in Table 1. For comparison, we include data from an axisymmetric simulation carried out with a geometry analogous to the "closed bypass" case described in [1]. As in the experiment, the pressure $p_{1}$ is measured near the bottom of the pumping port below the gas source. The value of $p_{2}$ is taken near the outer wall of the main chamber. Because of the iterative approach used to treat neutral-neutral collisions, the usual Monte Carlo estimates of the error in $p_{1}$ and $p_{2}$ (a few percent or smaller) provide only a lower bound on the precision of these numbers. Since the conductance involves the difference of the pressures, its uncertainty is even larger. Consequently, care should be exercised in comparing nearly equal conductance values.

The conductance in the "open" port simulations is larger than the measured value of $4.5 \mathrm{~m}^{3} / \mathrm{s}$. Because the pressure differential is smaller in this run than in the "closed" port cases, more flights have been used to increase the precision; the observed discrepancy is unlikely to be the result of Monte Carlo noise.

The conductance in the baseline "closed" port simulation is smaller than the measured value of $1.2 \mathrm{~m}^{3} / \mathrm{s}$. Decreasing the poloidal gap from 4 to $2 \mathrm{~mm}$ lowers the conductance slightly. Three runs not included in Table 1 are worth mentioning briefly, but do not merit the space required to describe them adequately. First, removing the poloidal and narrow toroidal gaps entirely yields a much smaller conductance, $\sim 0.5 \mathrm{~m}^{3} / \mathrm{s}$. Second, two runs in which the sink strength and location are varied yield main chamber pressure changes consistent with Eq. (3); the conductance is not noticeably altered in either case.

\section{Discussion}

Our first conclusion is that detailed 3-D simulations of neutral gas transport in fusion devices are possible and, in some cases, practical given the availability of massively parallel computers.

To compare the axisymmetric result with the 3 -D conductances, we imagine spreading the source uniformly amongst the ten C-Mod bays. We can compute an effective conductance using the average of the ten pressures we would find at each of the pumping ports. We can get these 
from the conductances in Table 1 and the common $p_{2}$. Using the simulated (experimental) conductances, we find $15(19) \mathrm{m}^{3} / \mathrm{s}$. We thus conclude that the axisymmetric geometry is effectively much more "open" than the actual 3-D geometry, explaining, at least in part [2], the too-low neutral pressures seen in [1]. The simulated 3-D "open" and "closed" port conductances are in comparatively better agreement with the experimental values of Sec. 3 [3].

Yet, the remaining differences merit closer examination. That the simulated "open" conductance is too high while the "closed" case is too low suggests that the differences may be due to not-simulated details in the geometry and experimental arrangement. The results of Sec. 2.1 urge us to consider also the nature of the gas flow in these simulations. Lowering the source strength by a factor of 16 yields only a slightly lower conductance, suggesting that the particle flow in the "closed" port case is nearly molecular. The dimensions of these gaps range from $3 \times 10^{-3}$ to $\sim 5 \times 10^{-2} \mathrm{~m}$. Using $p_{1}$ from the baseline run yields $K \sim 0.05 \rightarrow 1$. In the "open" case, $d \sim 6 \times 10^{-2} \mathrm{~m}$, yielding $K=0.1$.

This range of Knuden numbers encompasses the $K=0.1$ value corresponding to the $Q_{1}=0.4$ $\mathrm{J} / \mathrm{s}$ simulations of Sec. 2.1 and Fig. 1. Since that case is sensitive to the spatial resolution of the opening, we suspect that the C-Mod simulations may be as well. These simulations used 4 zones in the toroidal direction to span the $6^{\circ}$ ports; only one zone covers the "closed" port's $3 \mathrm{~mm}$ toroidal gap. Additional runs could be done to assess the sensitivity of the conductance to the level of toroidal, and poloidal, resolution. Inadequate spatial resolution is also the most likely explanation for the last entry in Table 1 in which raising the source strength a factor of 4 results in a $d r o p$ in the conductance, not an increase as we would expect from Fig. 1.

\section{Acknowldegments}

The authors would like to thank S. A. Klasky for producing the visualization shown in Fig. 3. This work supported by U.S. DOE Contracts DE-AC02-CHO3073 and DE-FC02-99ER54512.

\section{References}

[1] D. P. Stotler et al., J. Nucl. Mater. 290-293 (2001) 967.

[2] S. W. Lisgo, Ph.D. thesis, University of Toronto (2003).

[3] B. LaBombard, C. J. Boswell, Tech. Rep. PSFC/RR-03-6, Massachusetts Institute of Technology, Plasma Science and Fusion Center.

[4] D. P. Stotler, C. F. F. Karney, Contrib. Plasma Phys. 34 (1994) 392.

[5] L. Holland, W. Steckelmacher, J. Yarwood (Eds.), Vacuum Manual, E. \& F. N. Spon, London, 1974.

[6] D. Reiter, et al., J. Nucl. Mater. 241-243 (1997) 342.

[7] R. J. Kanzleiter, et al.,Phys. Plasmas 8 (2000) 5064.

[8] C. May, Tech. Rep. JUEL-3486, Forschungszentrum Jülich, in German (1997). 


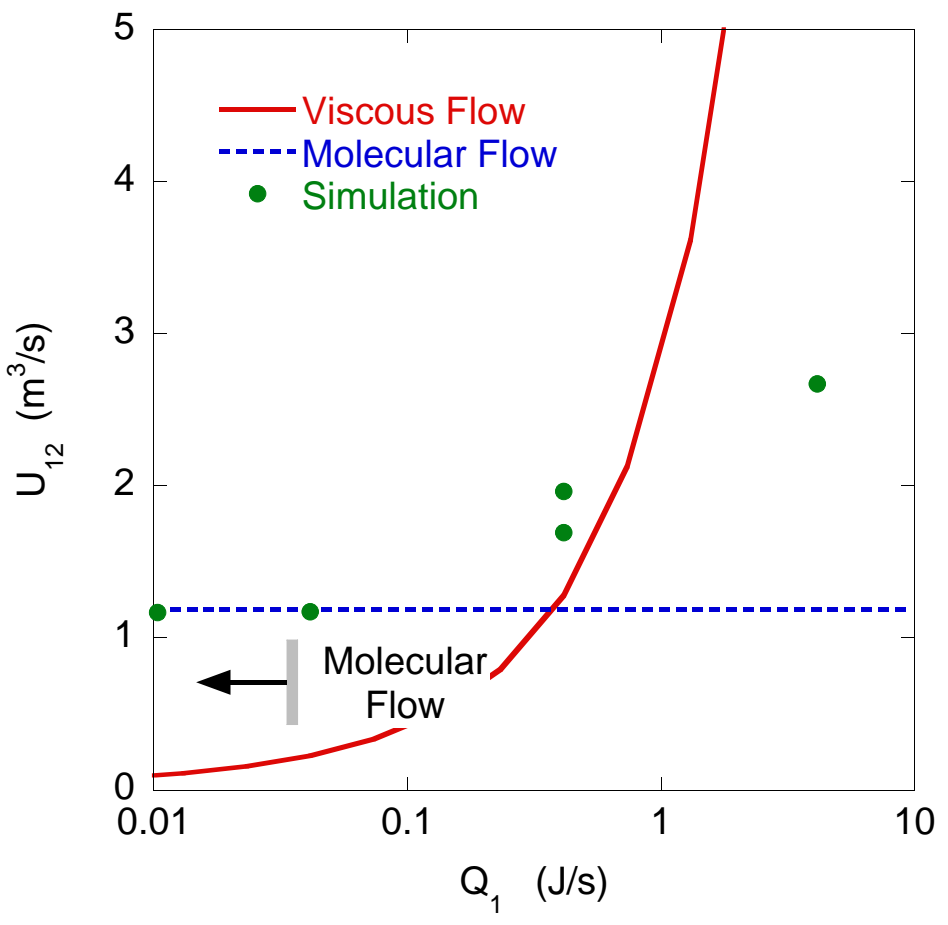

Figure 1. Comparison of simulated and reference conductances for a $0.205 \mathrm{~m} \mathrm{long}, 0.1 \mathrm{~m}$ square pipe as a function of gas source strength. The gray bar indicates the approximate boundary between the molecular flow and transition regimes. The viscous flow regime begins at $Q \simeq 40 \mathrm{~J} / \mathrm{s}$. 


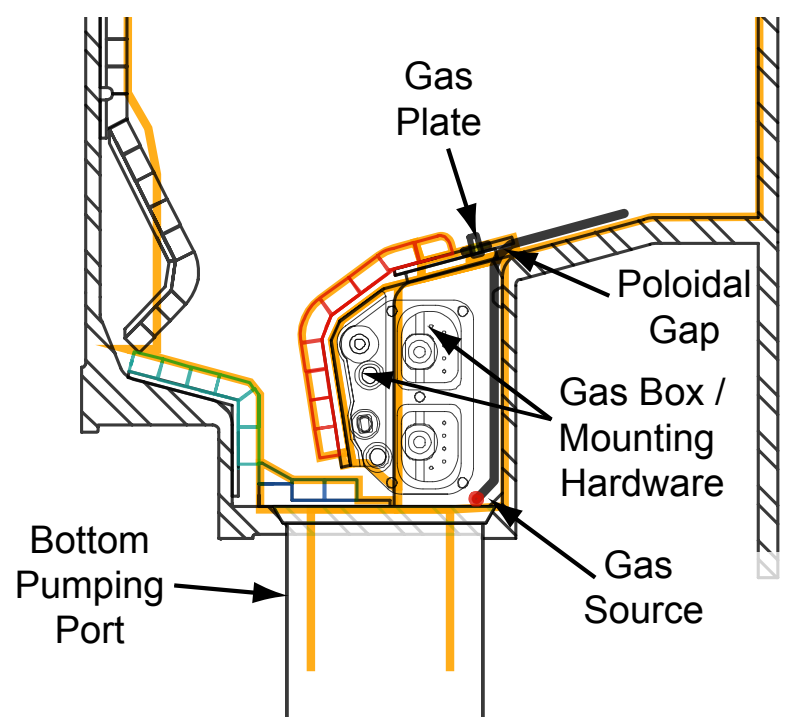

Figure 2. The plane polygons used to construct the 3-D DEGAS 2 Alcator C-Mod geometry, shown in orange, are overlayed on an engineering drawing of the actual C-Mod lower divertor cross section[3]. Note that the later shows the previous configuration for the inner divertor; the DEGAS 2 representation is derived from the current configuration. 


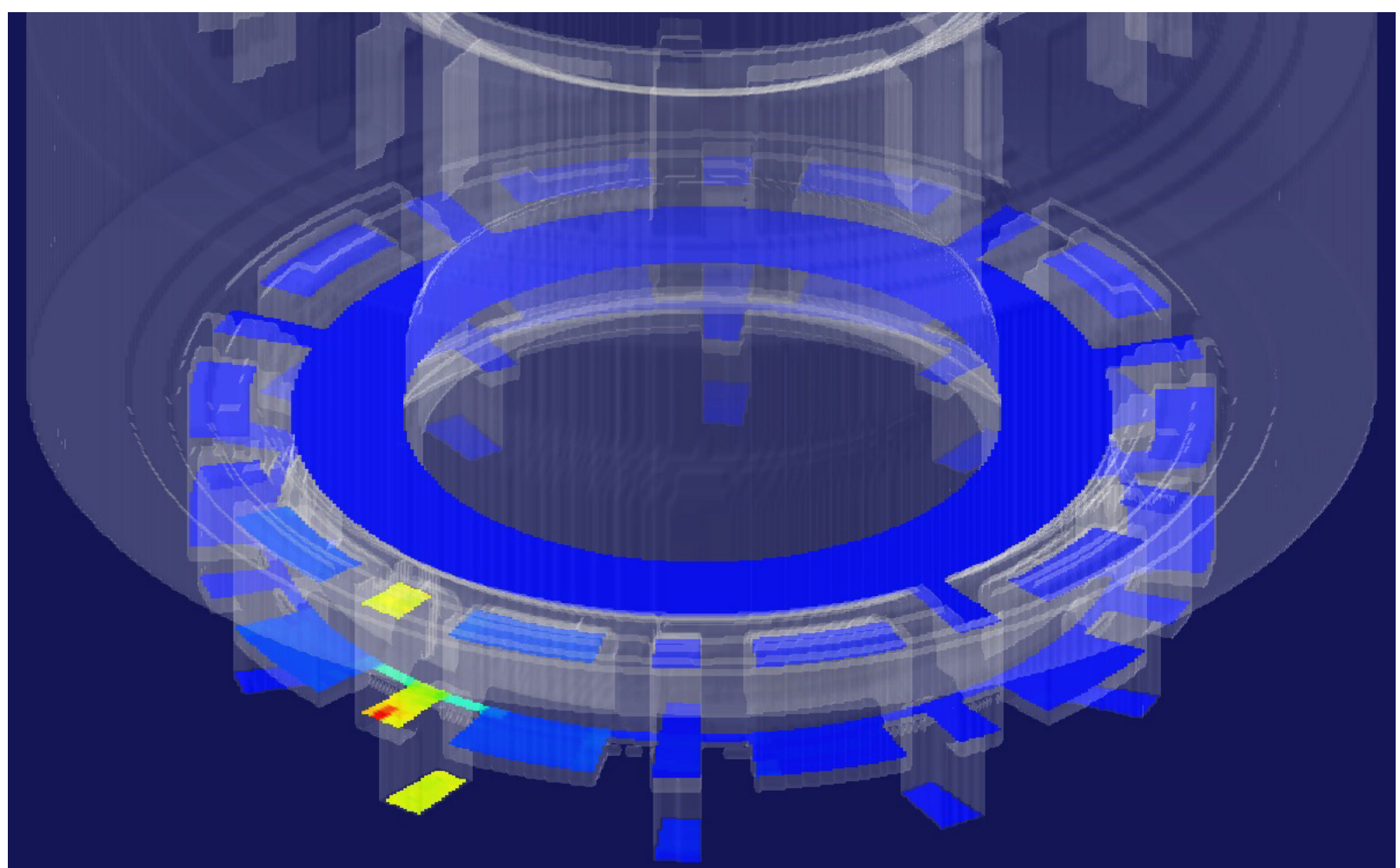

Figure 3. Visualization of simulated neutral pressure from the closed port C-Mod simulation. The pale white surface is the isosurface of an arbitrarily low pressure value and essentially outlines the hardware locations. The three $Z=$ constant orthoslices pass through the bottom pumping ports, the bottom of the gas box (at the source location), and the top of the gas box. The same color map is used in all three slices. 


\section{External Distribution}

Plasma Research Laboratory, Australian National University, Australia

Professor I.R. Jones, Flinders University, Australia

Professor João Canalle, Instituto de Fisica DEQ/IF - UERJ, Brazil

Mr. Gerson O. Ludwig, Instituto Nacional de Pesquisas, Brazil

Dr. P.H. Sakanaka, Instituto Fisica, Brazil

The Librarian, Culham Laboratory, England

Mrs. S.A. Hutchinson, JET Library, England

Professor M.N. Bussac, Ecole Polytechnique, France

Librarian, Max-Planck-Institut für Plasmaphysik, Germany

Jolan Moldvai, Reports Library, Hungarian Academy of Sciences, Central Research Institute for Physics, Hungary

Dr. P. Kaw, Institute for Plasma Research, India

Ms. P.J. Pathak, Librarian, Institute for Plasma Research, India

Ms. Clelia De Palo, Associazione EURATOM-ENEA, Italy

Dr. G. Grosso, Instituto di Fisica del Plasma, Italy

Librarian, Naka Fusion Research Establishment, JAERI, Japan

Library, Laboratory for Complex Energy Processes, Institute for Advanced Study, Kyoto University, Japan

Research Information Center, National Institute for Fusion Science, Japan

Dr. O. Mitarai, Kyushu Tokai University, Japan

Dr. Jiangang Li, Institute of Plasma Physics, Chinese Academy of Sciences, People's Republic of China

Professor Yuping Huo, School of Physical Science and Technology, People's Republic of China

Library, Academia Sinica, Institute of Plasma Physics, People's Republic of China

Librarian, Institute of Physics, Chinese Academy of Sciences, People's Republic of China

Dr. S. Mirnov, TRINITI, Troitsk, Russian Federation, Russia

Dr. V.S. Strelkov, Kurchatov Institute, Russian Federation, Russia

Professor Peter Lukac, Katedra Fyziky Plazmy MFF UK, Mlynska dolina F-2, Komenskeho Univerzita, SK-842 15 Bratislava, Slovakia

Dr. G.S. Lee, Korea Basic Science Institute, South Korea

Institute for Plasma Research, University of Maryland, USA

Librarian, Fusion Energy Division, Oak Ridge National Laboratory, USA

Librarian, Institute of Fusion Studies, University of Texas, USA

Librarian, Magnetic Fusion Program, Lawrence Livermore National Laboratory, USA

Library, General Atomics, USA

Plasma Physics Group, Fusion Energy Research Program, University of California at San Diego, USA

Plasma Physics Library, Columbia University, USA

Alkesh Punjabi, Center for Fusion Research and Training, Hampton University, USA

Dr. W.M. Stacey, Fusion Research Center, Georgia Institute of Technology, USA

Dr. John Willis, U.S. Department of Energy, Office of Fusion Energy Sciences, USA

Mr. Paul H. Wright, Indianapolis, Indiana, USA 
The Princeton Plasma Physics Laboratory is operated by Princeton University under contract with the U.S. Department of Energy.

\author{
Information Services \\ Princeton Plasma Physics Laboratory \\ P.O. Box 451 \\ Princeton, NJ 08543
}

Phone: 609-243-2750

Fax: 609-243-2751

e-mail: pppl_info@pppl.gov

Internet Address: http://www.pppl.gov 